\title{
Multiple Oct2 isoforms are generated by alternative splicing
}

Thomas Wirth ${ }^{1,2 \star}$, Annette Priess ${ }^{1}$, Arnd Annweiler ${ }^{1}$, Stefan Zwilling ${ }^{1}$ and Barbara Oeler ${ }^{1}$

${ }^{1}$ Zentrum für Molekulare Biologie, der Universität Heidelberg (ZMBH), Im Neuenheimer Feld 282, 6900 Heidelberg, FRG and Basel Institute for Immunology, Grenzacherstraße 487, 4005 Basel, Switzerland

Received October 8, 1990; Revised and Accepted December 3, 1990

\begin{abstract}
The interaction of the Oct2 transcription factor with the cognate octamer motif ATGCAAAT is a critical determinant of the lymphoid-specific expression of immunoglobulin genes. Ectopic expression of cloned Oct2 CDNA was shown to be sufficient to reconstitute at least some aspects of this regulation in non-lymphoid cells. We describe the isolation and characterization of multiple cDNAs encoding mouse Oct2 from a mature B-cell line and we show that a variety of isoforms of this transcription factor is generated from a single gene by an alternative splicing mechanism. All the isoforms retain the previously characterized POU-domain and are therefore able to bind to the octamer motif. Different amounts of the various isoforms are present within the same B-cell regardless of the developmental stage of B-cell differentiation and at least some of the isoforms are conserved between mouse and humans. In cotransfection experiments we show that all the isoforms are able to activate an octamer containing promoter element in fibroblasts revealing an unexpected functional redundancy. Finally, we show that one of the isoforms encodes the previously described lymphoid-specific Oct2B protein which has been suggested to be involved in the function of the octamer motif in the context of the immunoglobulin heavy-chain $(\mathbf{I g H})$ enhancer.
\end{abstract}

\section{INTRODUCTION}

The lymphoid-specific expression of immunoglobulin genes is regulated by at least two distinct cis-acting regulatory elements, the upstream promoter and the intronic enhancer element $(1,2$, $3,4)$. The octamer motif ATGCAAAT or its reverse complement ATTTGCAT is conserved both in the intronic heavy-chain enhancer as well as in all heavy and light-chain gene promoters $(5,6)$. It contributes to the lymphoid-specific activity of the enhancer (7) and plays a pivotal role for immunoglobulin promoter activity $(8,9,10)$.

However, the octamer motif is not exclusively associated with regulatory elements involved in lymphoid-specific expression.
It has also been found to play an important role in the regulation of ubiquitously expressed genes. Cell cycle regulation of histone H2B gene expression has been shown to be governed by the same octamer motif (11). Transcription of genes encoding several of the small nuclear RNAs (UsnRNAs) by both RNA polymerase II and III is also dependent on a functional upstream octamer motif $(12,13)$. Furthermore, the octamer element has also been implicated in adenovirus replication (14).

Several proteins that interact with the conserved octamer motif have been identified and characterized to different extents. Oct 1 (other names are NF-A1, OTF1, OBP 100, NFIII) is a 90-100kD protein which seems to be ubiquitously expressed $(15,16,17,18)$. Two lymphoid-specific octamer binding proteins have been described: Oct2A (other designations OTF2, NF-A2), a protein of $55-60 \mathrm{kD}(19,20,21)$ and Oct2B (OTF2B) a $75 \mathrm{kD}$ protein that has been shown by a proteolytic clipping electrophoretic mobility shift assay to be related to Oct2A (22). Oct4 (NF-A3, Oct3) has been detected as a protein specifically expressed in undifferentiated embryonal stem cells and embryonal carcinoma cell lines $(7,23,24)$. In addition, various other octamer binding proteins have been identified in extracts from different cell types and tissues $(23,25,26)$.

Recently, cDNA clones were obtained for Oct1, Oct2A and Oct4 $(17,24,27,28,29,30,31)$. Analysis of these clones revealed that they are members of a novel class of homeo-box containing transcription factors characterized by the presence of a POU-domain. The POU-domain was originally described as a region of homology conserved in the mammalian transcription factors Pit-1, Oct-1 and Oct-2 as well as the Caenorhabditis elegans unc-86 gene. It consists of a POU-specific (75-80 amino acids long) and a POU-homeo (60 amino acids long) subdomain separated by a short linker $(17,32)$. cDNAs encoding additional POU-domain proteins have been isolated using a PCR cloning protocol (33). It is not clear, however, whether these cDNAs encode some of the octamer binding proteins already described (23). Results of site directed mutagenesis and deletion experiments suggested that this POU-domain in its entirety is responsible for the sequence-specific DNA-binding as well as for protein-protein interactions $(34,35,36,37)$.

Comparison of the independently isolated human Oct2A cDNA

\footnotetext{
* To whom correspondence should be addressed
} 
sequences revealed that the cDNAs isolated from the BJA-B cell line encode a protein that contains an insert of 16 amino acids that is absent from the protein encoded by the cDNA clone isolated from Namalwa cells $(28,29,38)$. It was unclear whether the two forms originated by transcription of highly related genes or whether the difference was due to the presence of two alleles or an alternative splicing mechanism. Here we report the isolation and characterization of multiple functional isoforms of Oct2 cDNA from murine B-cells. We show that they are generated by an alternative splicing mechanism. Among the isolated isoforms are both homologues of the two described human cDNAs and a clone encoding Oct2B.

\section{MATERIALS AND METHODS}

Isolation of cDNA clones

The mouse pre B-cell library (kind gift of Dr. P. Nielson, MPI Freiburg) in $\lambda g t 11$ was independently screened with two endlabelled 61 base long oligonucleotides. These oligonucleotides were homologous to the published human Oct2A sequence from position 889 to 950 and from 997 to 1058, respectively (28). For PCR amplification the following two primer oligonucleotides were used:

Oct 5': CTGGATCCGGGCAGCATGGTCGACTCCAGCATGGGGGCTCCAG

Oct 3': AGGAATTCGAGGGGAGGCATGGCCGGCTCTCACTCAGCCTTGG

The 5' primer contains a BamHI cloning site upstream and a SalI site downstream of the AUG start codon, the $3^{\prime}$ primer contains an EcoRI cloning site. First strand cDNA was prepared from $2 \mu \mathrm{g}$ of total cytoplasmic WEHI231 RNA using oligo(dT) primers and MuLV Reverse Transcriptase (Gibco-BRL). 10\% of this

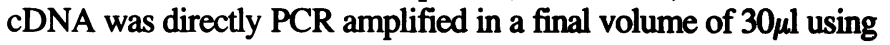
20 pmol of the $5^{\prime}$ and 3 ' primers each. PCR amplifications were done with 1 unit of Taq-polymerase (Perkin Elmer) for $\mathbf{4 0}$ seconds at $94^{\circ} \mathrm{C}, 1 \mathrm{~min}$ at $65^{\circ} \mathrm{C}, 2.5 \mathrm{~min}$ at $72^{\circ} \mathrm{C}(3$ cycles) followed by 40 cycles of 40 seconds at $94^{\circ} \mathrm{C}, 3 \min 72^{\circ} \mathrm{C}$. The amplified DNA was precipitated, digested with EcoRI and BamHI and cloned into the BluescriptSK ${ }^{-}$vector. 90 clones containing Oct2 sequences were selected for further analyses. DNA was digested with MspI which yields about 15-20 fragments that could be resolved on $40 \mathrm{~cm}$ polyacrylamide gels. This analysis allowed classification of 70 of the clones into the classes described (Oct2.1-Oct2.6). The remaining 20 clones were single isolates and have not been characterized further.

\section{Isolation of genomic clones}

Complete Oct2 cDNA inserts were used for screening of a mouse 129 strain cosmid library (kind gift of A. Poustka) and a single cosmid was repeatedly isolated. As this cosmid was lacking the first 3 coding exons, we constructed a $\lambda E M B L 3$ genomic library from C57BI/6 mouse spleen DNA. $2 \times 10^{6}$ phages from the unamplified library were screened using a probe containing the first 180bp of the Oct2 cDNA and two phages containing nonoverlapping inserts were isolated. One of them was contiguous with the previously isolated cosmid clone and contained exons 2 and 3 . The other started about $2 \mathrm{~kb}$ upstream of the first phage insert (determined by genomic Southern blots with several enzymes) and contained exon 1.

\section{Subcloning and sequencing}

Fragments from the genomic clones were subcloned into the pBluescriptSK- vector. For sequence analysis multiple additional subclones were generated for dideoxy sequencing with M13 universal/reverse primers. In addition several oligonucleotides were generated from the Oct2 cDNA sequence and used for sequencing. Sequencing was done on double stranded DNA using dITP as well as standard nucleotides and T7 DNA Polymerase (Pharmacia) according to manufacturers specifications.

In vitro transcription and translation, electrophoretic mobility shift assays (EMSA)

cDNA containing plasmids $(1 \mu \mathrm{g})$ were linearized with EcoRI and RNA was synthesized using T3 RNA polymerase according to manufacturers instructions (Stratagene). In vitro translation with $1 \mu \mathrm{g}$ of RNA was performed in rabbit reticulocyte lysates (Promega) following manufacturers specifications. $10 \mu \mathrm{Ci}{ }^{35} \mathrm{~S}-$ labelled methionine was included in the reactions. 1/25 of the in vitro translation was analyzed on a $10 \%$ SDS polyacrylamide gel. As probes for the EMSA, wild-type or mutant octamer oligonucleotides cloned into the BamHI site of pUC18 and subsequently excised with EcoRI/HindIII were used (19). Binding reactions contained $50 \mathrm{mM} \mathrm{NaCL}, 10 \mathrm{mM}$ Tris/HCl pH 7.5, $1 \mathrm{mM}$ DTT, $1 \mathrm{mM}$ EDTA, $5 \%$ glycerol, $3 \mu \mathrm{g}$ poly(dI-dC), 5000 $\mathrm{cpm}$ of the respective probe and $1 / 25$ of the in vitro translation reaction. Native gels were run in $0.5 \times$ TBE buffer, dried and exposed for $12 \mathrm{hrs}$ with two layers of paper interleaved to suppress signals originating from the labelled proteins.

\section{Cell and tissue culture and transfections}

Lymphoid cells were maintained in Iscove's modified DMEM supplemented with $5 \%$ fetal calf serum, $10 \mu \mathrm{M} \beta$-mercaptoethanol and antibiotics. NIH/3T3 cells were grown in DMEM supplemented with 5\% calf serum, $5 \%$ newborn calf serum and antibiotics. For mitogen stimulations spleen single cells (about $5 \times 10^{6}$ cells $/ \mathrm{ml}$ ) were stimulated with either $30 \mu \mathrm{g} / \mathrm{ml}$ lipopolysaccharide (Sigma) or with $3 \mu \mathrm{g} / \mathrm{ml}$ concanavalinA (Sigma) for $\mathbf{4 8} \mathrm{hrs}$. Transfections were done by the calcium. phosphate co-precipitation method. $2 \times 10^{6}$ cells were transfected with $5 \mu \mathrm{g}$ of the reporter plasmids plus $2 \mu \mathrm{g}$ of the Oct 2 cDNA expression constructs. Sheared salmon sperm DNA was added to adjust the amount of transfected DNA to $20 \mu \mathrm{g} .4 \mathrm{hrs}$ after the addition of the DNA precipitate a DMSO shock was performed. Cytoplasmic RNA was prepared $44 \mathrm{hrs}$ later as described (39).

\section{RNA analysis}

$\mathrm{S} 1$ analysis with the mouse histone $\mathrm{H} 4$ probe was performed as described (10).

For primer extension analysis $30 \mathrm{mg}$ of cytoplasmic RNA was coprecipitated with 0.01 pmol (typically about $25,000 \mathrm{cpm}$ ) of 5 ' end labelled primer (5'GGGGTTGTGAGTCCAGATCGATCTG3'). Hybridization was performed in $10 \mu \mathrm{l}$ of $250 \mathrm{mM} \mathrm{KCl}$, $10 \mathrm{mM}$ Tris/ $\mathrm{HCl} \mathrm{pH7.5,} 1 \mathrm{mM}$ EDTA for $1 \mathrm{hr}$ at $60^{\circ} \mathrm{C}$, then $40 \mu \mathrm{l}$ of $1 \times$ Reverse Transcriptase buffer containing $0.5 \mathrm{mM}$ of each dNTP, $0.1 \mathrm{mg}$ BSA and $200 \mathrm{U}$ MuLV Reverse Transcriptase (Gibco-BRL) was added. Reactions were terminated after $1 \mathrm{hr}$ at $37^{\circ} \mathrm{C}$, precipitated and analyzed on $10 \%$ denaturing polyacrylamide gels.

RNase protection analysis was essentially performed as described (40). RNA from primary cells and organs was isolated 
by the guanidinium-isothiocyanate/ $\mathrm{CsCl}$ centrifugation method (40). Cytoplasmic RNA from cell lines was prepared as described (39). Typically 10 to $30 \mu \mathrm{g}$ RNA was hybridized to $500,000 \mathrm{cpm}$ of RNA probe synthesized by transcription with either T3 or T7 RNA polymerase. Protected fragments were analyzed on $6 \%$ denaturing polyacrylamide gels.

\section{Western analysis}

$150 \mu \mathrm{g}$ of nuclear proteins prepared as described (41) were separated on a $10 \%$ SDS polyacrylamide gel (40) and then electrophoretically transferred for $2 \mathrm{hrs}$ at $80 \mathrm{~V}$ to a nitrocellulose membrane using a BioRad transblot cell. The membrane was stained with PonceauS to visualize the molecular weight standards and was blocked using $2 \%$ dry milk after destaining. The blots were reacted with mouse antisera raised against bacterially produced Oct 2 isoforms (42) and subsequently with an alkaline phosphatase coupled goat anti-mouse antibody (Jackson laboratories). The blots were developed as described (42).

\section{RESULTS}

Multiple Oct2 related RNA species are present in B-cells Initially we had isolated a partial Oct 2 cDNA clone by standard techniques from a murine pre B-cell library using oligonucleotides homologous to the POU-specific region and the POUhomeodomain of the published human Oct2A cDNA sequence as probes (38). This clone did not extend to the amino terminus of the coding region (data not shown). We subsequently used oligonucleotide primers from within this partial cDNA clone and primers that were either homologous to the amino terminal

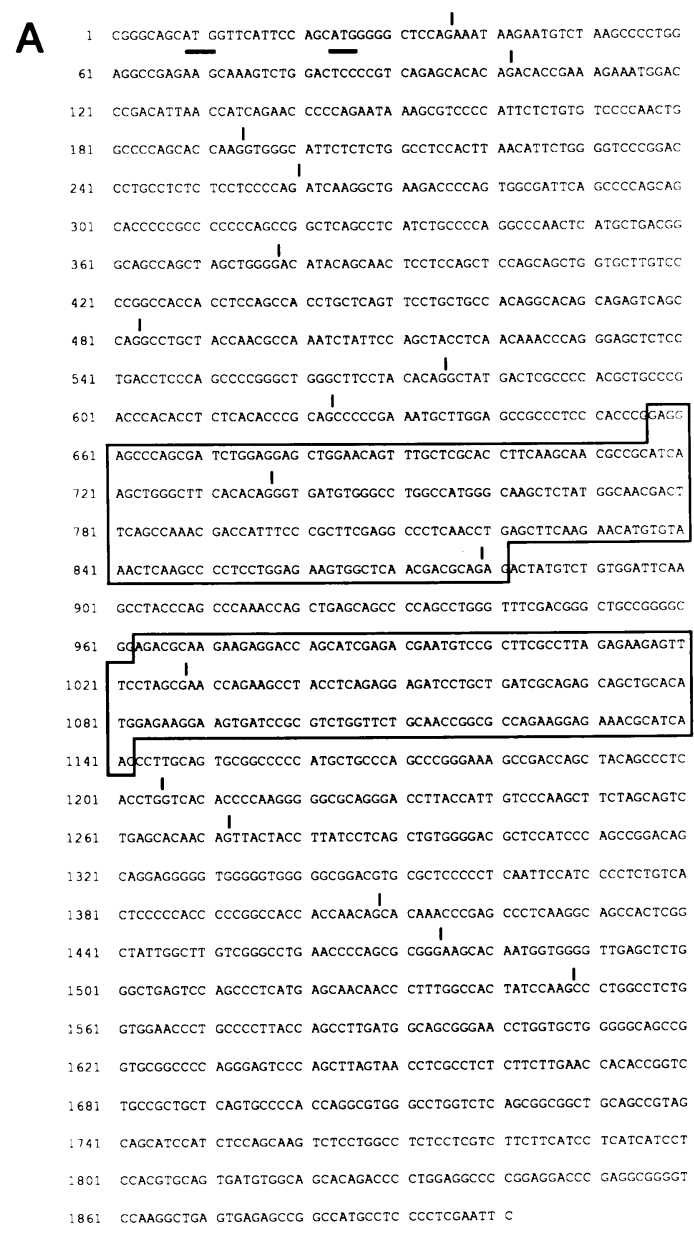

B

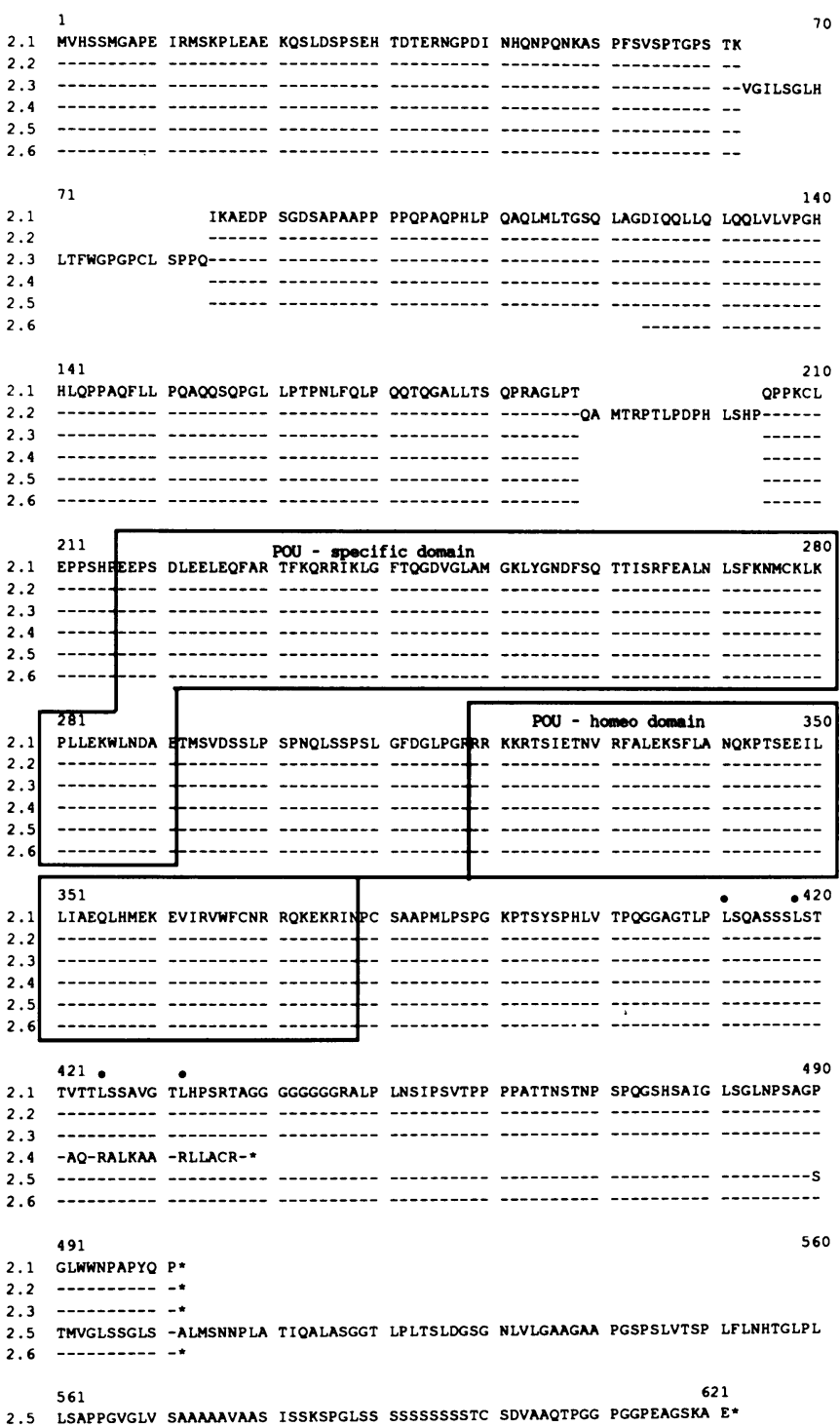

Figure 1: Nucleotide and protein sequences of the various Oct2 isoforms. A.) The composite nucleotide sequence of the mouse cDNAs is shown. The sequence starts 8 or $23 \mathrm{bp}$ upstream of the AUG startcodon, depending on which one of the two in frame AUG codons is used (AUG codons underlined). The sequence of the first $40 \mathrm{bp}$ is actually taken from the genomic clones because the oligonucleotide used for PCR amplification contained several point mutations in order to introduce convenient cloning sites. The regions encoding the POU-specific domain and the POU-homeo domain are boxed, positions of splice sites used to generate the various isoforms are indicated by vertical lines. B.) Predicted amino-acid sequences of the six Oct2 proteins. The full sequence of the major Oct2 form (Oct2.1) is shown, for the other isoforms only the divergent sequences are shown. Identical amino-acids are indicated by dashes $(-)$, stop codons are indicated by asterisks. The POUspecific and the POU-homeo domain are boxed again, the 4 leucine residues that constitute the presumptive leucine zipper are hallmarked by dots. 
sequence of the human CDNA or the $3^{\prime}$ end of the cloned murine cDNA to amplify Oct 2 cDNA sequences by PCR. Surprisingly, we obtained alternate forms of both the $5^{\prime}$ as well as the $3^{\prime}$ end (data not shown). In order to determine which $5^{\prime}$ ends would be associated with which $3^{\prime}$ ends, we used the PCR technique to amplify the complete murine homologue of the published human cDNA (for experimental details, see Materials and Methods section). The amplified DNA was subcloned into a plasmid vector and 90 independent clones containing Oct2 sequences were selected for further analyses. Using frequently cutting restriction enzymes, we were able to classify about $80 \%$ of these cDNAs into 6 different forms. At least two isolates for each form were obtained. The remaining $20 \%$ of the cDNA clones were single isolates and not characterized further. More than half $(63 \%)$ of the repeatedly isolated clones belonged to the class designated Oct2.1. The other forms were present at lower frequencies comprising between 3\% (Oct2.6) and 12\% (Oct2.3) of the clones. Figure 1 shows the composite nucleotide sequences and a summary of the deduced amino acid sequences of the 6 forms (Oct2.1-Oct2.6) characterized in this report. The dominant form (Oct2.1) is $\mathbf{9 8 . 5 \%}$ identical to the human Oct2 clone isolated from Namalwa cells (29). Oct2.2 shares the same degree of identity with the Oct 2 clones isolated from the human BJA-B cell line $(28,38)$. The difference between the two clones is due to an in frame insert of $48 \mathrm{bp}$ (16 aa) that are present in form Oct2.2 but not in Oct2.1 (nor in any of the other Oct2 variants). The other Oct 2 variants have not yet been described. Oct2.3 has an in frame insert of $66 \mathrm{bp}$ (22aa) close to the amino terminus of the gene. Oct 2.6 shows an in frame deletion of $117 \mathrm{bp}$ (39aa) starting at the insertion site of the extra $66 \mathrm{bp}$ of variant Oct2.3 and extending towards the carboxy terminus of the protein. The alterations in Oct2.4 and Oct2.5 are both localized $3^{\prime}$ of the conserved POU-domain and change the reading frame. Oct2.4 lacks 136bp and runs into a stop codon 17aa downstream of the deletion site. This modification destroys the putative leucine zipper $(28,29,38)$. Oct 2.5 contains a 74 bp insert 12aa upstream of the termination codon of variants Oct2.1, Oct2.2, Oct2.3 and Oct2.6. Due to this insertion and the resulting frame shift, this variant encodes 132 new amino acids at the carboxy terminus. The predicted molecular weights of the proteins encoded by the variant forms indicate that Oct2.1, Oct2.2 and Oct2.3 with molecular weights of approximately 57,59 and $60 \mathrm{kD}$ could be considered Oct2A type proteins (21). With a predicted molecular weight of $75 \mathrm{kD}$, Oct 2.5 is a prime candidate to encode the previously described Oct2B protein (22). No lymphoid specific octamer binding proteins with molecular weights corresponding to the smaller Oct2.4 and Oct2.6 forms (49 and 52kD, respectively) have been described.

Variant Oct2 isoforms are generated by alternative splicing In order to determine whether these variant forms were encoded by different genes or generated by a post-transcriptional mechanism, we isolated genomic cosmid and phage clones covering the region represented in the cDNAs. Analysis of the genomic DNA established that the Oct 2 protein encoding portion of the cDNAs is spread over more than $35 \mathrm{~kb}$ of a single gene locus and is split into a total of 14 exons (Figure 2A). It should be noted that due to the way the CDNA clones were isolated, they do not extend to the ends of Oct 2 mRNA. Interestingly, all the Oct 2 protein encoding information extends over only $1.8 \mathrm{~kb}$ whereas in a Northern analysis with B-cell RNA, several poly $\left(\mathrm{A}^{+}\right)$RNA species that range in size from 6.5 to $2 \mathrm{~kb}$ can be detected $(27,28,38)$; data not shown). At present, it is unclear

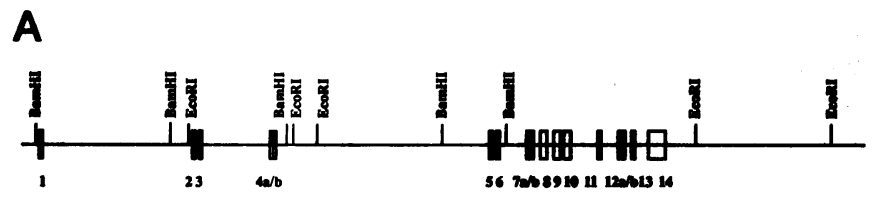

$\overline{\mathbf{a b}}$

B

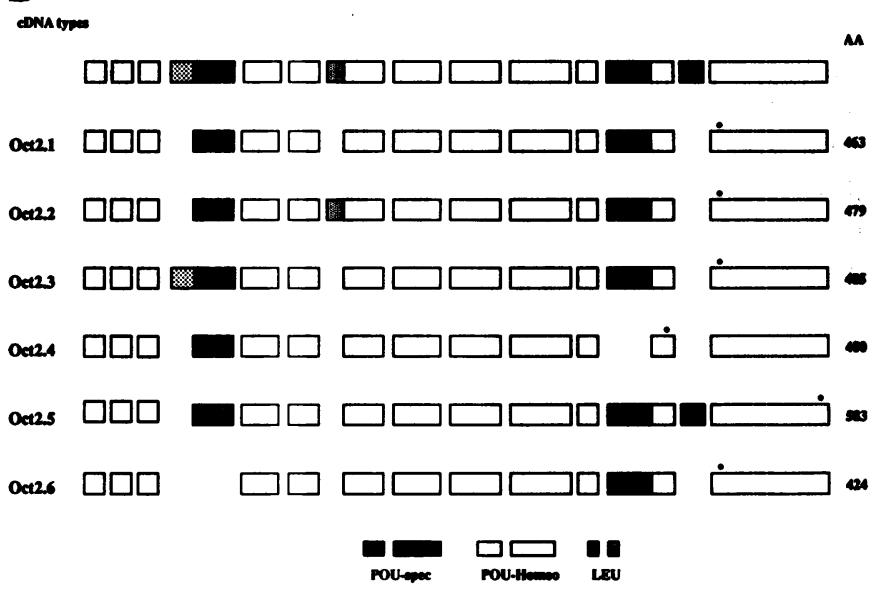

Figure 2: Exon/Intron structure of the coding region of the mouse Oct2 gene. A.) The restriction map of about 50kb genomic DNA is shown. The sizes of the exons (open boxes) are not drawn to scale. $a / b$ indicates that due to the use of alternative splice acceptors different parts of the same exon are present in different cDNAs. B.) Schematic representation of the exon structure of the six Oct2 isoforms. The top line shows the 14 exons utilized by the various forms, the exon composition of the individual isoforms is shown below. The regions encoding the POU-specific domain, the POU homeo domain and the putative leucine zipper are indicated below the figure. The position of the translational stop codon predicted for the various isoforms is shown as a black dot above the respective exon, the length of each of the proteins (starting with the first in frame AUG) is given to the right of every isoform.

whether the missing extensions are attached to the $5^{\prime}$ or $3^{\prime}$ end of the cloned cDNAs.

A comparison of the exon sequences of the genomic and cDNA clones revealed that the two in frame insertions in clones Oct2.2 and Oct2.3 as well as Oct 2.4 are generated by using alternative splice acceptor sites (Figure 2B). Oct2.6 is generated by skipping exon 4. The 74bp insert present in the Oct2.5 isoform represents an autonomous miniexon that is spliced out in all the other isoforms (Figure 2B).

Both the POU-specific as well as the POU-homeo domains are split by an intron (Figures 1B and 2B). The position of the intron in the POU-specific subdomain does not correspond to the short stretch of amino acids that separates the POU-A and the POU-B regions (35) but rather splits the POU-A region. In addition, the leucine zipper region localized $3^{\prime}$ to the POU-domain is also split by an intron (Fig. 2B).

The frequencies with which the different isoforms occurred in the pool of cloned cDNAs indicated that they might not be present in equimolar amounts in WEHI231 cells. Therefore RNase protection assays that allowed us to distinguish between the different Oct 2 forms were performed to measure their relative frequencies (Fig. 3A). We were readily able to detect the appropriate protected fragments for isoforms Oct2.2, Oct2.3 and Oct2.5 as well as Oct2.4 in addition to Oct2.1 which represents the dominant form in WEHI231 RNA (Fig. 3B and 3C). The 


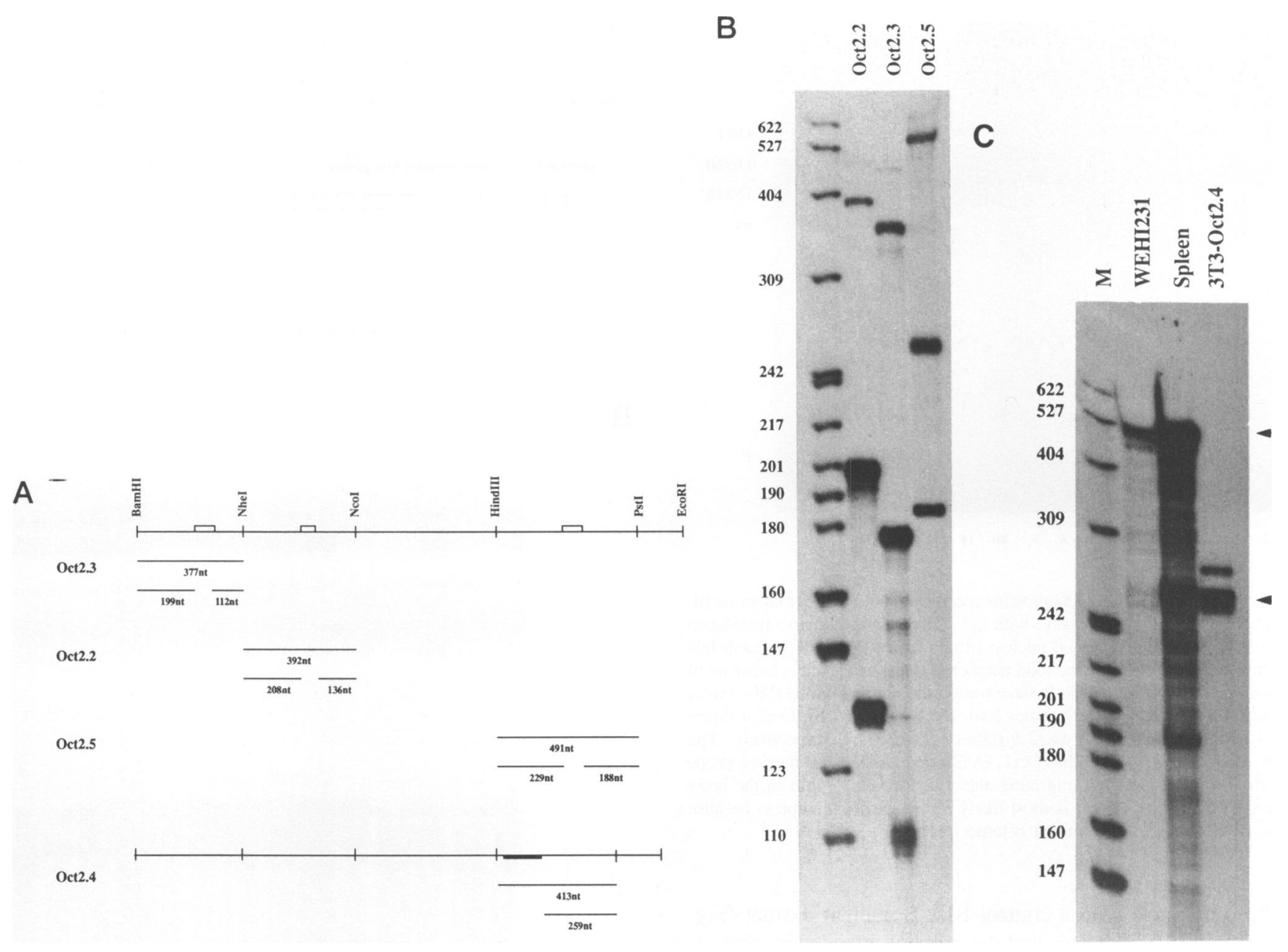

Figure 3: RNA corresponding to the different isoforms are present at varying levels in B-cells. A.) Schematic representation of the fragments that are predicted to be protected from RNase degradation. The large fragment represents the Oct 2 cDNA fragment subcloned into the pBluescript $\mathrm{SK}^{-}$vector used to generate the probe. The actual probe size is 50 to 60 nt longer than the size of the largest protected fragment due to the presence of polylinker sequences. The open boxes indicate the extra sequences present in the Oct2.2, Oct2.3 and Oct2.5 forms, respectively, the black box indicates the region missing in the Oct2.4 cDNA. Correspondingly for Oct2.2, Oct2.3 and Oct2.5 the largest protected fragment is indicative for the respective RNA whereas in the case of Oct2.4 the presence of the shorter protected fragment is indicative for the respective RNA. The other protected fragments are indicative for all the Oct2 RNAs except the specific form. B.) RNase protection with the Oct2.2, Oct2.3 and Oct2.5 probes using 30mg cytoplasmic WEHI231 RNA. The marker shown in the left lane is an endlabelled MspI digest of pBR322 DNA. In all cases an additional fragment corresponding to residual undigested probe is seen above the largest protected fragment. C.) RNase protection with the Oct2.4 probe and RNA isolated from either WEHI231 cells, total spleen (50 $\mu \mathrm{g}$ each) or NIH/3T3 cells stably transformed with an Oct2.4 expression construct (20 $\mu \mathrm{g})$. The positions of the correct protected fragments are indicated by arrowheads. As the stably transformed cells only express Oct 2.4 the large protected fragment indicative for the forms Oct2.1-3 and Oct2.5-6 is absent in this lane.

two larger fragments in the Oct 2.5 specific protection experiment show a somewhat aberrant running behavior by migrating too slowly in the gel system used (even more pronounced in Figure 6 , see below). These bands represent the correct protected fragments, however, as comigrating bands were specifically obtained by RNase protection using RNA from fibroblast cells transfected with either Oct2.1 or Oct2.5 cDNA expression constructs (data not shown, for structure of the expression constructs see Figure 5A). RNA corresponding to isoform Oct2.6 could only be detected using a PCR protocol and an amplification primer specific for the indicative junction of the Oct2.6 cDNA (data not shown).

From densitometric scanning of the autoradiographs in Figure $3 \mathrm{~B}$ and $3 \mathrm{C}$ we calculate that Oct 2.2 is present at a frequency of roughly $5 \%$ of total Oct2 RNA whereas Oct 2.3 and Oct2.5 make up about $11 \%$ and $18 \%$ of the Oct2 RNA, respectively. Oct2.4 represents about $8 \%$ and Oct2.6 is very infrequent making up less than $1 \%$ of the Oct2 RNA. From these numbers we estimate that Oct 2.1 makes up about $55 \%$ and therefore represents the majority of the Oct2 RNA present in WEHI231 cells. These numbers are good reflections of the frequencies with which the clones were originally detected in the PCR cloning protocol (with the noted exception of Oct2.6) arguing for the general validity of the approach.

\section{Oct2 isoforms are functional transcription factors}

The deduced amino acid sequences shown in Figurel suggest that the different isoforms encode proteins of quite distinct sizes. This was verified both by overexpression of the individual isoforms in a bacterial expression system as well as by in vitro translation in reticulocyte lysates (data not shown). When used in an electrophoretic mobility shift assay (EMSA) specific complexes with an octamer containing probe were obtained with all six isoforms (Fig. 4). A comparison of the retarded complexes 


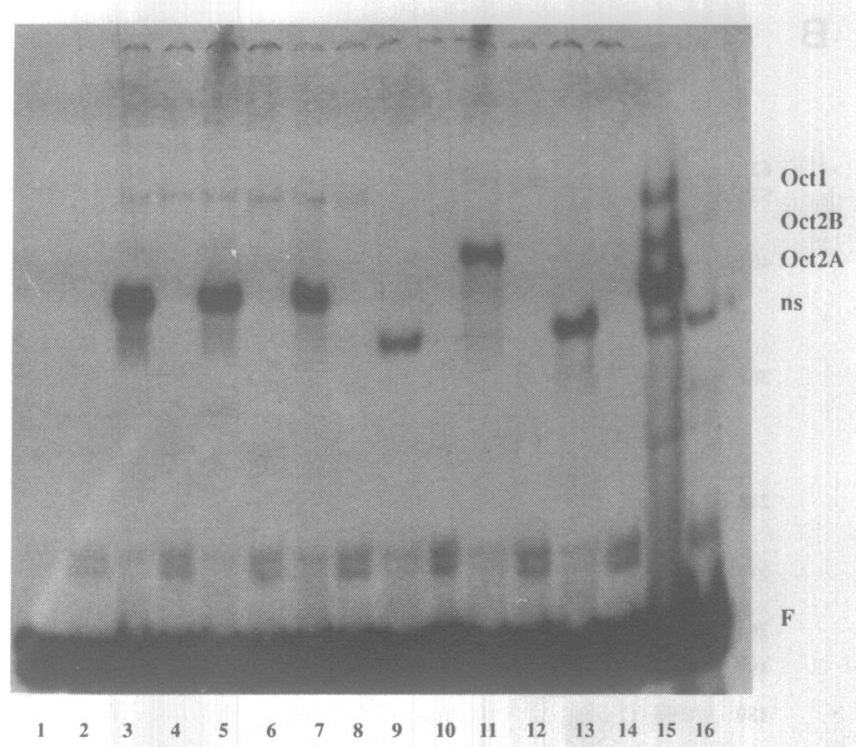

Figure 4: In vitro synthesized Oct2 proteins specifically bind to the octamer motif. Electrophoretic mobility shift assays with $2 \mu \mathrm{l}$ aliquots of the in vitro translation reactions (lanes 1-14) or a BJA-B nuclear extract (lanes 15,16). A radiolabelled probe containing either a wild type (odd numbered lanes) or mutant octamer motif (even numbered lanes) was used. In vitro translation without added RNA (lanes 1,2 ), Oct2.1 (lanes 3,4), Oct2.2 (lanes 5,6), Oct2.3 (lanes 7,8), Oct2.4 (lanes 9,10 ), Oct2.5 (lanes 11,12) or Oct2.6 (lanes 13,14) RNA, respectively. The positions of the known Oct2 shifts (Oct1, Oct2B and Oct2A) and the free probe (F) are marked. The complex migrating ahead of the Oct2A shift in the lanes with the BJA-B nuclear extract is most likely a non-specific complex, because it is also detectable with the mutant octamer probe.

with those obtained with a control BJA-B nuclear extract (Fig. 4 , lanes 15 and 16) indicates that the proteins encoded by Oct2.1, Oct2.2 and Oct2.3 all shift the wild-type probe to a position similar to the Oct2A complex present in BJA-B nuclear extracts (Fig. 4, lanes 3,5,7 and 15). This indicates that the previous designation Oct2A does not describe a single protein but rather a family of similar sized proteins. The Oct2.5 protein shifts the probe to a position that corresponds to the position of the Oct2B band shift (compare lanes 11 and 15 in Fig. 4B). This comigration is still observed when the gels are run much further to yield a higher resolution (data not shown). This comigration in the EMSA together with the observed size of Oct2.5 in the SDSpolyacrylamide gel strongly suggests that Oct 2.5 encodes the previously described Oct2B protein. Oct2.4 and Oct2.6 proteinDNA complexes migrate faster than the Oct2A protein-DNA complexes and have not been described previously (Fig. 4B, lanes 9 and 13). There is a complex of similar mobility visible with the BJA-B extract used. However, this complex is not specific for the wild-tpye octamer probe, because it is also present when the mutant probe is used (Fig. 4B, lanes 15 and 16). A specific complex that could potentialy comigrate with the Oct2.4/Oct2.6 protein-DNA complexes termed Oct2C is observed in some BJAB nuclear extract preparations, however (E. Schreiber, pers. communication). This complex might be hidden underneath the non-specific shift present in our extracts.

The ability of the different Oct2 isoforms to activate transcription was tested in a cotransfection assay. The human Oct2A cDNA (corresponding to our Oot2.2 isoform) had previously been shown to be able to stimulate an octamer promoter construct in non-lymphoid cells (28). Oct2 cDNAs were introduced into a cytomegalovirus enhancer/promoter based
A
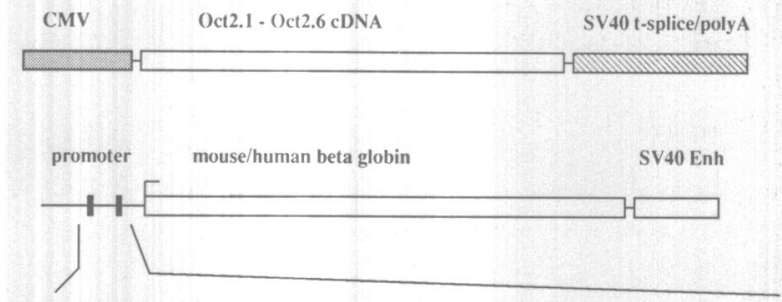

GTCGACTCTAGAGGATCATGCAAATGATCCCCGATCTGGGGCAGAGCATATAAGGTGAGG GTCGACTCTAGAGGATCATTCAAATGATCCCCGATCTGGGGCAGAGCATATAAGGTGAGG

B

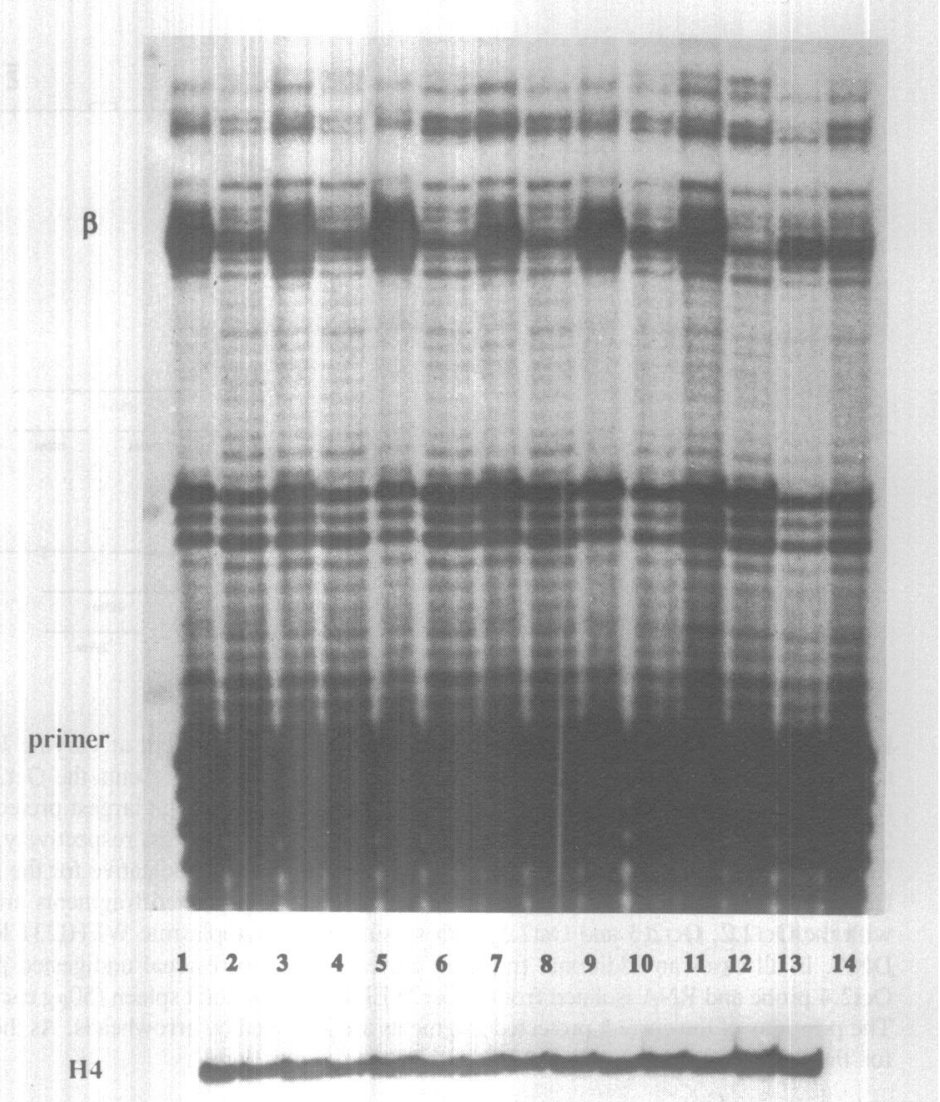

Figure 5: The various Oct2 isoforms can activate an octamer containing promoter. A.) Scheme of the cytomegalovirus enhancer/promoter Oct2 expression constructs and the reporter plasmids. The reporter plasmids also contained the polyoma virus early region to allow for replication in mouse cells and modified mouse histone H4 gene used as a reference to control for differences in the transfection efficiencies. The sequences of the wild type (top) and mutant (bottom) octamer promoters are shown. The octamer element and the TATA-motif in the promoter are highlighted, the position of the point mutation in the octamer element is indicated. B.) Primer extension/nuclease S1 analysis of RNA form NIH/3T3 cells co-tranfected with the various Oct 2 expression constructs (Oct2.1, lanes 1,2; Oct2.2, lanes 3,4; Oct2.3, lanes 5,6; Oct2.4, lanes 7,8; Oct2.5, lanes 9,10; Oct2.6, lanes 11,12 ) or the expression vector without an Oct2 cDNA insert (lanes 13,14) and either the wild type (odd numbered lanes) or mutant (even numbered lanes) octamer promoter reporter constructs. The upper panel shows the $\beta$-globin primer extension analysis, the lower panel shows the nuclease $S 1$ analysis specific for the histone $\mathrm{H} 4$ reference. Positions of the correct fragments for the $\mathrm{H} 4$ and $\beta$ globin analyses as well as the primer are marked. Additional bands visible above the correctly extended fragment in the $\beta$-globin primer extension analysis most likely originate from readthrough transcription of the replicating plasmids. 
eukaryotic expression vector. The AUG codon was provided by the vector and 6 amino acids encoded by the vector polylinker replaced the first two amino acids of Oct2 (Fig. 5A). The reporter plasmids containing either a wild-type or a point mutant version of the octamer motif upstream of the $\beta$-globin TATA-box and the modified $\beta$-globin gene have been described previously (10). The reporter plasmids also contain a modified mouse histone $\mathrm{H} 4$ gene that allows correction for different transfection efficiencies. NIH/3T3 fibroblast cells were cotransfected and RNA was isolated for quantitative analysis $48 \mathrm{hrs}$ later. From the results obtained it is evident that all 6 isoforms can stimulate the wildtype octamer promoter construct whereas the constructs containing a mutant octamer motif remain unaffected (Fig. 5B, lanes $1-12$ ). Furthermore, it is obvious that the stimulation depends on the expression of the Oct cDNA because a control cotransfection with the expression vector lacking an Oct2 cDNA insert does not give this stimulatory effect (Fig.5B, lanes 13,14).

Oct2 splicing pattern is conserved in murine B-cell development and also between species

The various Oct2 isotypes had all been isolated from the WEHI231 cell line which represents a surface immunoglobulin positive B-cell. It was of interest to determine whether B-cells at other differentiation stages would express the same set of Oct2 isoforms or whether there would be developmental stage specific alternative splicing of Oct 2 mRNA. As representatives of different stages of the B-cell lineage we chose the HAFTL I, 70Z/3 (early and late pre B-cells, resp.), WEHI231 (mature Bcells) and X63Ag8/653 (plasma cells) cell lines. RNase protection analysis of cytoplasmic RNA from the different cell lines with probes detecting Oct2.2, Oct2.3 and Oct2.5 in addition to Oct2.1 clearly shows that the Oct2 splicing pattern is conserved throughout the B-cell lineage (Figure 6A). Furthermore it is evident that although the overall quantities of Oct2 RNA are lower in the cell lines representing the earlier stages of B-cell development, the relative frequencies of the individual isoforms are roughly the same in all cell lines tested. The same result was obtained when a probe specific for Oct2.4 was used or PCR analysis with an Oct2.6 specific primer was performed (data not shown).

We also analyzed Oct2 expression in different lymphoid organs to exclude the possibility that the observed alternative splicing is the consequence of continuous growth of cells in culture. RNase protection analysis of total RNA isolated from bone marrow, thymus, spleen, and mitogen stimulated spleen cells reveals that in all these primary samples the multitude of Oct2 isoform expression is conserved (Figure 6B). Again the relative frequencies of different Oct 2 isoforms are comparable whereas the overall amounts of Oct2 RNA vary in the different organs. The detection of the full range of Oct2 isotypes in bone marrow RNA is consistent with the previous observation that pro and pre B-cell lines already express the various Oct2 isoforms. The presence of Oct2 RNA in thymus and ConA stimulated spleen cells suggests that primary T-cells actually express Oct 2 . Clearly the strongest expression of Oct2 is observed in spleen and lipopolysaccaride (LPS) stimulated spleen cells. However, it is interesting that mitogen stimulation does not lead to a significant increase of Oct2 RNA expression.

The previous isolation of two Oct2A cDNAs from the human BJA-B cell line corresponding to the mouse Oct 2.1 and Oct2.2 isoforms indicated that the alternative splicing pattern is conserved even between mouse and human. To further extend this observation we investigated whether the mouse Oct2.5/Oct2B
A

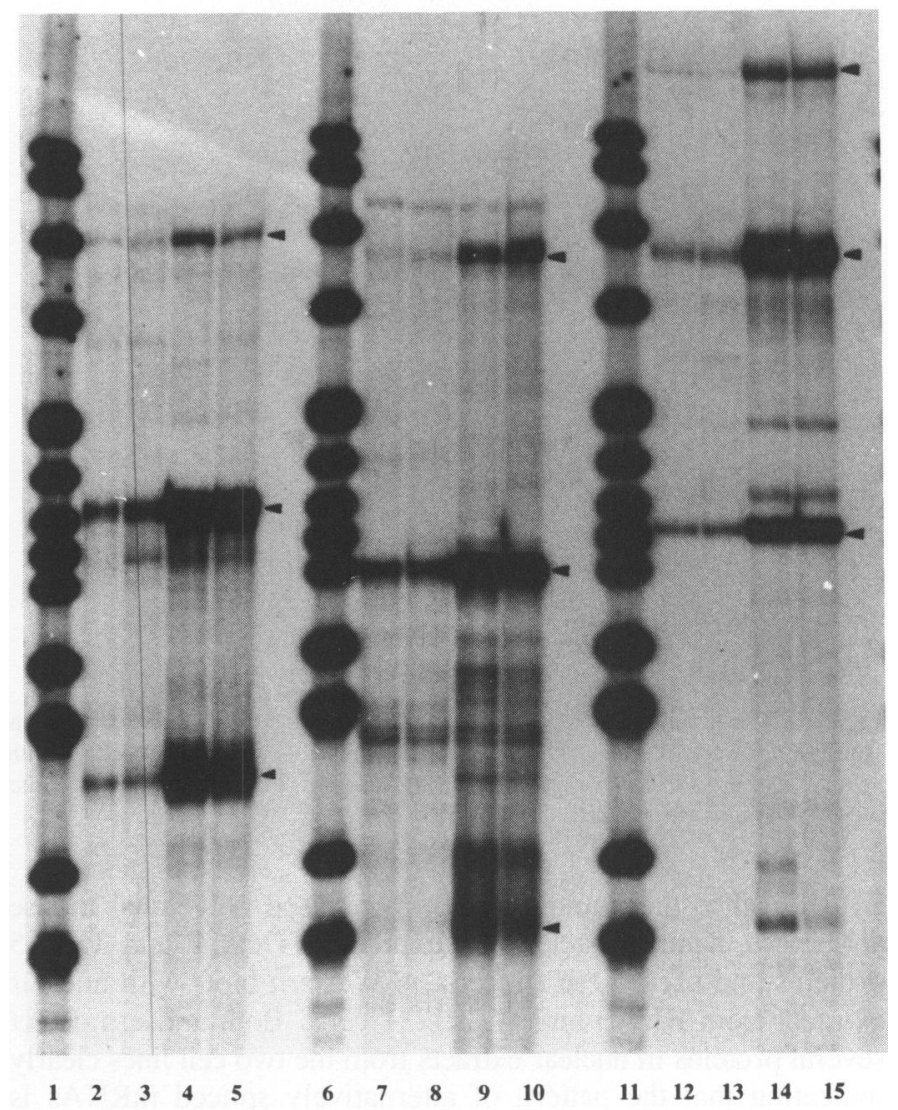

B

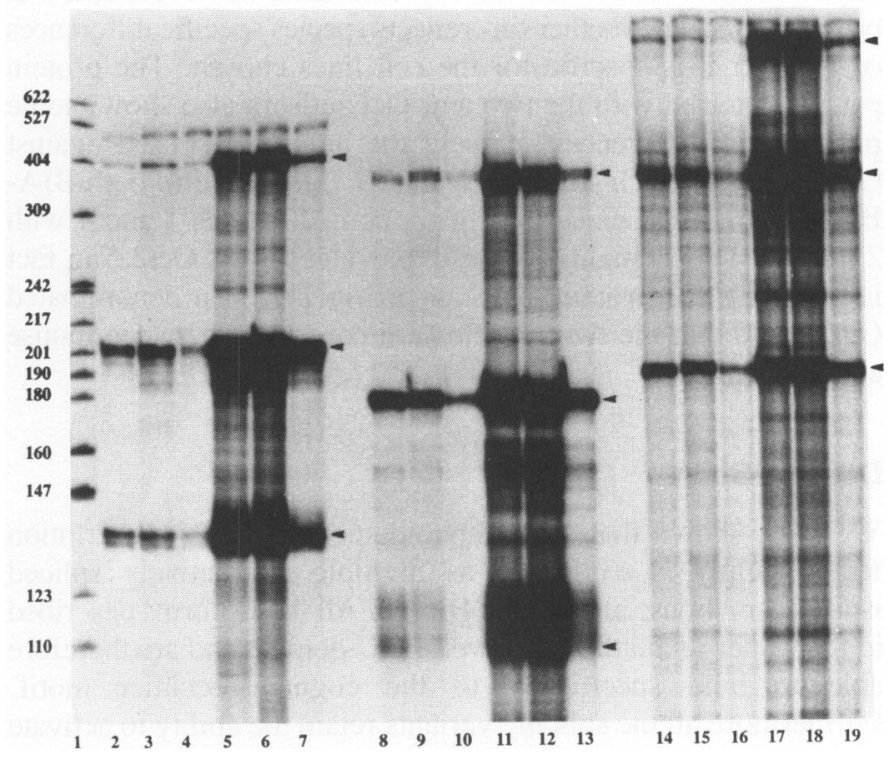

Figure 6: Expression of Oct 2 isoforms in different B-cell lines and lymphoid organs. A.) RNase protection analysis with the Oct2.2 (lanes 2-5), Oct2.3 (lanes $7-10$ ) and Oct 2.5 (lanes $12-15$ ) specific probes. $30 \mu \mathrm{g}$ cytoplasmic RNA from HAFTL/I (lanes 2,7,12), 70Z/3 (lanes 3,8,13), WEHI231 (lanes 4,9,14) and X63Ag8/653 cells (lanes $5,10,15$ ) were used. The position of the correct protected fragments is indicated by arrowheads. The marker lanes are endlabelled MspI digests of pBR322 DNA. B.) RNase protection analysis with RNA from various organs. The same probes as above were used (Oct2.2: lanes 2-7; Oct2.3: lanes 8-13; Oct2.5: lanes 14-19). 25 $\mu$ g of cytoplasmic WEHI231 RNA (lanes 2,8,14) or $50 \mu \mathrm{g}$ total RNA from the following sources were used: bone marrow: lanes $3,9,15$; thymus: $4,10,16$; spleen: lanes $5,11,17$; spleen/LPS: lanes $6,12,18$; spleen/ConA: lanes 7,13,19; 


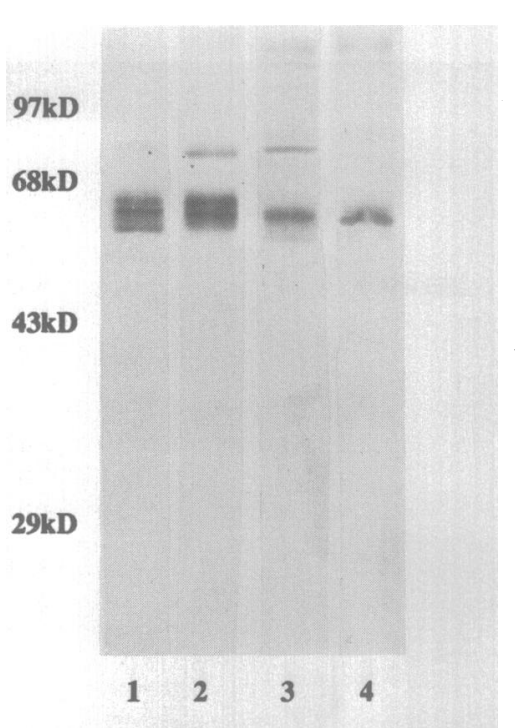

Figure 7: Western blot analysis with anti-Oct2 antisera. $150 \mu \mathrm{g}$ of nuclear proteins from BJA-B (lanes 1,2) and WEHI231 cells (lanes 3,4) were reacted either with an anti-Oct2.4 (lanes 1,4) or an anti-Oct2.5 antiserum. Positions of the molecular weight markers are marked.

is identical to the human Oct2B. We raised polyclonal mouse antibodies against bacterially expressed Oct2.4 and Oct2.5 proteins and used these antisera on Western blots with nuclear extracts from BJA-B and WEHI231 cells. Both antisera detect several proteins in nuclear extracts from the two cell lines clearly indicating that the pattern of alternatively spliced mRNAs is actually mirrored at the protein level (Fig. 7). The pattern is slightly different between the two cell lines, however, and it is presently unclear whether this reflects species specific differences or whether it is specific for the cell lines chosen. The protein pattern detected with the two anti-Oct antisera also shows some pronounced differences, namely the antiserum raised against Oct2.5 reacts much stronger against a $75 \mathrm{kD}$ band in both BJAB and WEHI 231 extracts (Fig. 7, compare lanes 1 and 4 with 2 and 3). This is highly suggestive evidence that Oct 2.5 in fact is encoding the protein that had previously been denominated Oct2B and that the two proteins are conserved between mouse and human.

\section{DISCUSSION}

We have shown that the lymphoid-specific Oct 2 transcription factor family is expressed as multiple alternatively spliced isoforms in mouse and human B-cells. All the isoforms described in this paper retain the conserved POU-domain and are therefore able to bind specifically to the cognate octamer motif. Furthermore all the splicing variants retain the ability to activate an octamer containing promoter in a cotransfection assay. Our analyses also show that the pattern of alternative splicing is conserved throughout the murine B-cell lineage and probably also in at least a subset of T-lymphocytes.

\section{Multiplicity of octamer binding proteins}

The octamer motif turns out to be a multi-functional regulatory element recognized by a variety of different proteins. So far, at least three genes encoding octamer binding proteins (Oct1, Oct2 and Oct4) have been cloned $(17,24,27,28,29,30,31)$. Additional octamer binding proteins have been identified, but it is at present unclear whether they are encoded by separate genes (23). Multiple genes coding for distinct transcription factors interacting with a conserved motif have been described for proteins binding to the CCAAT-box, the AP-1 site, and the cAMP response element (CRE) $(44,45,46,47,48,49)$. We show here that alternative splicing is responsible for the generation of a multitude of Oct 2 isoforms. Preliminary evidence suggests that the Oct4 gene might also code for two protein isoforms, Oct4 and Oct5, due to the usage of alternate translational initiation codons (30). Alternative splicing as a mechanism to generate multiple isoforms of transcriptional regulators has also been described for the CTF/NF-I transcription factor (45), the CREB transcription factor (50), as well as for the drosophila ultrabithorax (Ubx) gene (51). Differential activities for alternate forms have been desribed for both CREB and CTF/NF-I (50, 52). Another striking homology between the CCAAT-box and octamer binding proteins is the fact that members of either family can function in stimulation of both transcription and replication $(52,53)$.

\section{Possible functions of the various Oct2 isoforms}

The Oct2 transcription factors could be differentially involved in several aspects during B-cell ontogeny. One of the first characteristics of a committed precursor of the B-cell lineage is the transcription of unrearranged heavy-chain genes (sterile $\mu$ transcription). It has recently been demonstrated that the octamer element in the heavy-chain enhancer plays an important role for this sterile $\mu$ transcription (54). The next important step in Bcell development is the rearrangement of the heavy-chain locus. Binding of Oct2 to its recognition sites in the heavy-chain enhancer and the $V_{H}$-promoters could be a critical event preceding this rearrangement. In this respect it is of interest that the $\mathrm{V}_{\mathrm{H}}$-promoters contain a high- and a low-affinity binding site for Oct2, the octamer and the heptamer motif $(55,56)$, and Oct2 binding to these two sites shows cooperativity $(43,57)$. Although this cooperative binding has been shown in vitro using purified bacterially expressed Oct 2 protein corresponding to Oct2.2 (43) it is not known what type of Oct 2 protein binds to these motifs under in vivo conditions.

If different Oct2 isoforms have different functions during Bcell development one might have expected to observe changes in the Oct2 RNA splicing pattern. Although our analyses clearly show that this is not the case, this does not exclude functional differences of the various isoforms. One possibility could be that the Oct 2 isoforms are regulated specifically at the translational level. Interestingly, expression of the GHF-1/Pit-1 protein, another member of the POU domain gene family, has been suggested to be regulated at the translational level in development (58). Differential activation properties could also be the result of differential modifications of the various isoforms. It has recently been reported that differential phosphorylation of Oct1 and Oct2A are due to differences at the carboxy termini of the two proteins and that these differences correlate with the transactivation potential (59). Members of the Oct2 transcription factor family might also be recruited for specific functions as a consequence of specific protein-protein interactions. Interestingly, isoform Oct 2.4 is devoid of a functional leucine zipper, a structure that has been shown to be involved in proteinprotein interactions $(60,61,62,63)$. This model has been suggested to explain the differential activities of the Oct1 and Oct2 proteins which are coexpressed in lymphoid cells (64).

The observation that all the various Oct2 isoforms stimulate an octamer containing promoter in a cotransfection assay shows 
that all the variants could be functional transcription factors. This result is in agreement with previous mutational analyses of the Oct2A (Oct2.1 and Oct2.2, respectively) protein $(65,66)$ which indicates that deletion of either the region on the amino- or carboxy-terminal site of the POU domain does not significantly affect the transactivation function.

While this manuscript was in preparation, Hatzopoulos and colleagues published the cloning of a cDNA encoding mouse Oct2B (67). Their cDNA is essentially identical to our Oct2.5 cDNA supporting the conclusion drawn in this paper.

\section{ACKNOWLEDGEMENTS}

We would like to thank P. Nielson for the pre B-cell cDNA library, A. Poustka for the genomic cosmid library, H. KraftCzepa and P. Krammer for the pExNeo eucaryotic expression vector, H-R. Kiefer for the preparation of oligonucleotides used in the initial cloning and characterization of the Oct 2 cDNAs, E. Schreiber for communicating unpublished results, R. Pollwein, R. Herrera, C. Ullmer and T. Lernbecher for critical reading of the manuscript and G.P. Wee for help in preparing the manuscript. This work was supported by a grant from the BMFT. The Basel Institute for Immunology was founded and is supported by F. Hoffmann-La Roche Co. Ltd., CH-4005 Basel, Switzerland.

\section{REFERENCES}

1. Bergman, Y., Rice, D., Grosschedl, R. \& Baltimore, D. (1984) Proc. Natl. Acad. Sci. USA 81, 7041-7045.

2. Mason, J.O., Williams, G.T. \& Neuberger, M.S. (1985) Cell 41, 479-487.

3. Grosschedl, R. \& Baltimore, D. (1985) Cell 41, 885-897.

4. Picard, D. \& Schaffner, W. (1985) EMBO J. 4, 2831-2838.

5. Parslow, T.G., Blair, D.L., Murphy, W.J. \& Granner, D.K. (1984) Proc. Natl. Acad. Sci. USA 81, 2650-2654.

6. Falkner, F.G. \& Zachau, H.G. (1984) Nature 310, 71-74.

7. Lenardo, M., Pierce, J.W. \& Baltimore, D. (1987) Science 236, 1573-1577.

8. Dreyfus, M., Doyen, N. \& Rougeon, F. (1987) EMBO J. 6, 1685-1690.

9. Gerster, T., Matthias, P., Thali, M., Jiricny, J. \& Schaffner, W. (1987) $E M B O$ J. 6, 1323-1330.

10. Wirth, T., Staudt, L. \& Baltimore, D. (1987) Nature 329, 174-178.

11. LaBella, F., Sive, H.L., Roeder, R.G. \& Heintz, N. (1988) Genes Dev. 2, 32-39.

12. Mattaj, I.W., Lienhard, S., Jiricny, J. \& DeRobertis, E.M. (1985) Nature 316, $163-167$.

13. Carbon, P., Murgo, S., Ebel, J., Krol, A., Tebb, G. \& Mattaj, I.W. (1987) Cell 51, 71-79.

14. Pruijn, G.J.M., van Driel, W. \& van der Vliet, P.C. (1986) Nature 322, 656-659.

15. Singh, H., Sen, R., Baltimore, D. \& Sharp, P.A. (1986) Nature 319, 154-158.

16. Fletcher, C., Heintz, N. \& Roeder, R.G. (1987) Cell 51, 773-781.

17. Sturm, R.A., Das, G. \& Herr, W. (1988) Genes Dev. 2, 1582-1599.

18. O'Neill, E.A., Fletcher, C., Burrow, C.R., Heintz, N., Roeder, R.G. \& Kelly, T.J. (1988) Science 241, 1210-1213.

19. Staudt, L.M., Singh, H., Sen, R., Wirth, T., Sharp, P.A. \& Baltimore, D. (1986) Nature 323, 640-643.

20. Landolfi, N.F., Capra, J.D. \& Tucker, P.W. (1986) Nature 323, 548-551.

21. Scheidereit, C., Heguy, A. \& Roeder, R.G. (1987) Cell 51, 783-793.

22. Schreiber, E., Matthias, P., Müller, M.M. \& Schaffner, W. (1988) EMBO J. 7, 4221-4229.

23. Schöler, H.R., Hatzopoulos, A.K., Balling, R., Suzuki, N. \& Gruss, P. (1989) $E M B O$ J. 8, 2543-2550.

24. Okamoto, K., Okazawa, H., Okuda, A., Sakai, M., Muramatsu, M. \& Hamada, H. (1990) Cell 60, 461-472.

25. Cox, P.M., Temperley, S.M., Kumar, H. \& Goding, C.R. (1988) Nucl. Acids Res. 16, 11047-11056.

26. Barberis, A., Superti-Furga, G. \& Busslinger, M. (1987) Cell 50, 347-359.

27. Staudt, L.M., Clerc, R.G., Singh, H., LeBowitz, J.H., Sharp, P.A. \& Baltimore, D. (1988) Science 241, 577-580.
28. Müller, M.M., Ruppert, S., Schaffner, W. \& Matthias, P. (1988) Nature 336, 544-551.

29. Scheidereit, C., Cromlish, J.A., Gerster, T., Kawakami, K., Balmaceda, C.-G., Currie, R.A. \& Roeder, R.G. (1988) Nature 336, 551-557.

30. Schöler, H.R., Ruppert, S., Suzuki, N., Chowdhury, K. \& P. Gruss. (1990) Nature 344, 435-439.

31. Rosner, M.H., Vigano, M.A., Ozato, K., Timmons, P.M., Poirier, F., Rigby, P.W.J. \& Staudt, L.M. (1990) Nature 345, 686-692.

32. Herr, W., Sturm, R.A., Clerc, R.G., Corcoran, L.M., Baltimore, D., Sharp, P.A., Ingraham, H.A., Rosenfeld, M.G., Finney, M., Ruvkun, G. \& Horvitz, H.R. (1988) Genes Dev. 2, 1513-1516.

33. He, X., Treacy, M.N., Simmons, D.M., Ingraham, H.A., Swanson, L.W. \& Rosenfeld, M.G. (1989) Nature 340, 35-42.

34. Sturm, R.A. \& Herr, W. (1988) Nature 336, 601604

35. Stern, S., Tanaka, M. \& Herr, W. (1989) Nature 341, 624-630.

36. Kristie, T.M., LeBowitz, J.H. \& Sharp, P.A. (1989) EMBO J. 8, 4229-4238

37. Ingraham, H.A., Flynn, S.E., Voss, J.W., Albert, V.R., Kapiloff, M.S., Wilson, L. \& Rosenfeld, M.G. (1990) Cell 61, 1021-1033

38. Clerc, R.G., Corcoran, L.M., LeBowitz, J.H., Baltimore, D. \& Sharp, P.A. (1988) Genes Dev. 2, 1570-1581

39. Wirth, T. \& Baltimore, D. (1988) EMBO J. 7, 3109-3113.

40. Ausubel, F.M., Brent, R., Kingston, R.E., Moore, D.D., Seidman, J.G., Smith, J.A. \& Struhl, K. Current protocols in molecular biology (John Wiley \& Sons, New York, Chichester, Brisbane, Toronto, Singapore, 1989).

41. Dignam, J.D., Lebovitz, R.M. \& Roeder, R.G. (1983) Nucleic Acids Res. 11, 1475-1489.

42. Harlow, E. \& Lane, D. (1988) Antibodies: A laboratory manual. Cold Spring Harbor Laboratory,

43. LeBowitz, J.H., Clerc, R.G., Brenowitz, M. \& Sharp, P.A. (1989) Genes Dev. 3, 1625-1638.

44. Landschulz, W.H., Johnson, P.F., Adashi, E.Y., Graves, B.J. \& McKnight, S.L. (1988) Genes Dev. 2, 786-800.

45. Santoro, C., Mermod, N., Andrews, P.C. \& Tjian, R. (1988) Nature 334, 218-224.

46. Gil, G., Smith, J.R., Goldstein, J.L., Slaughter, C.A., Orth, K., Brown M.S. \& Osborne, T.F. (1988) Proc. Natl. Acad. Sci. USA 85, 8963-8967.

47. Zerial, M., Toschi, L., Ryseck, R.-P., Schuermann, M., Müller, R. \& Bravo, R. (1989) $E M B O$ J. 8, 805-813.

48. Ryder, K., Lau, L.F. \& Nathans, D. (1988) Proc. Natl. Acad. Sci. USA 85, 1487-1491.

49. Hai, T., Liu, F., Coukos, W.J. \& Green, M.R. (1989) Genes Dev. 3, 2083-2090.

50. Yamamoto, K.K., Gonzalez, G.A., Menzel, P., Rivier, J. \& Montminy, M.R. (1990) Cell 60, 611-617.

51. O’Connor, M.B., Binari, R., Perkins, L.A. \& Bender, W. (1988) EMBO J. 7, 435-445.

52. Mermod, N., O’Neill, E.A., Kelly, T.J. \& Tjian, R. (1989) Cell 58, $741-753$.

53. Verrijzer, C.P., Kal, A.J. \& Van der Vliet, P.C. (1990) EMBO J. 9, 1883- 1888 .

54. Su, L.-K. \& Kadesch, T. (1990) Mol. Cell. Biol. 10, 2619-2624.

55. Poellinger, L. \& Roeder, R.G. (1989) Mol. Cell. Biol. 9, 747-756.

56. Kemler, I., Schreiber, E., Müller, M.M., Matthias, P. \& Schaffner, W. (1989) EMBO J. 8, 2001-2008.

57. Poellinger, L., Yoza, B.K. \& Roeder, R.G. (1989) Nature 337, 573-576.

58. Dollé, P., Castrillo, J.-L., Theill, L.E., Deerinck, T., Ellisman, M. \& Karin M. (1990) Cell 60, 809-820.

59. Tanaka, M. \& Herr, W. (1990) Cell 60, 375-386.

60. Landschulz, W.H., Johnson, P.F. \& McKnight, S.L. (1989) Science 243, $1681-1688$.

61. Schuermann, M., Neuberg, M., Hunter, J.B., Jenuwein, T., Ryseck, R.P., Bravo, R. \& Müller, R. (1989) Cell 56, 507-516.

62. Turner, R. \& Tjian, R. (1989) Science 243, 1989-1694.

63. Gentz, R., Rauscher III, F.J., Abate, C. \& Curran, T. (1989) Science 243, 1695- 1699.

64. Schaffner, W. (1989) Trends Genetics 5, 37-39.

65. Gerster, T., Balmaceda, C. \& Roeder, R.G. (1990) EMBO J. 9, 1635-1643.

66. Müller-Immerglück, M.M., Schaffner, W. \& Matthias, P. (1990) EMBO J. 9, 1625-1634.

67. Hatzopoulos, A.K., Stoykova, A.S., Erselius, J.R., Goulding, M., Neuman, T. \& Gruss, P. (1990) Development 109, 349-362. 